\title{
The role of F9 fimbriae of uropathogenic Escherichia coli in biofilm formation
}

\section{Correspondence \\ Mark A. Schembri \\ m.schembri@uq.edu.au}

Received 26 November 2006

Revised 1 March 2007

Accepted 2 March 2007

\author{
Glen C. Ulett, ${ }^{1}$ Amanda N. Mabbett, ${ }^{1}$ Khe C. Fung, ${ }^{1}$ Richard I. Webb ${ }^{2}$ \\ and Mark A. Schembri ${ }^{1}$
}

\author{
${ }^{1}$ School of Molecular and Microbial Sciences, University of Queensland, Brisbane, \\ Queensland 4072, Australia \\ ${ }^{2}$ Centre for Microscopy and Microanalysis, University of Queensland, Brisbane, Queensland 4072, \\ Australia
}

\begin{abstract}
Uropathogenic Escherichia coli (UPEC) is the primary cause of urinary tract infection (UTI) in the developed world. The major factors associated with virulence of UPEC are fimbrial adhesins, which mediate attachment to specific receptors, enhance persistence and trigger innate host responses. UPEC produce a range of fimbrial adhesins, with type 1 and $P$ fimbriae of the chaperone-usher subclass being the best characterized. The prototype UPEC strain CFT073 contains ten gene clusters that contain genes characteristic of this class of fimbriae. However, only five of these gene clusters have been characterized in detail. In this study the F9 fimbrial gene cluster (c1931-c1936) from CFT073 has been characterized. The F9 fimbriae-encoding genes were PCR amplified, cloned and expressed in a K-12 background devoid of type 1 fimbriae. While F9 fimbrial expression was not associated with any haemagglutination or cellular adherence properties, a role in biofilm formation was observed. E. coli K-12 cells expressing F9 fimbriae produced a dense and uniform biofilm in both microtitre plate and continuous-flow biofilm model systems. In wild-type UPEC CFT073, expression of the F9 major subunit-encoding gene was detected during exponential growth in M9 minimal medium. F9 expression could also be detected following selection and enrichment for pellicle growth in a CFT073fim foc double mutant. The F9 genes appear to be common in UPEC and other types of pathogenic E. coli. However, their precise contribution to disease remains to be determined.
\end{abstract}

\section{INTRODUCTION}

Urinary tract infections (UTIs) are among the most common infectious diseases of humans and a major cause of morbidity. In the USA, UTI accounts for approximately $\$ 1.6$ billion in medical expenditure each year. It is estimated that $40-50 \%$ of healthy adult women have experienced at least one UTI episode in their lifetime (Foxman, 2002). The recurrence rate of UTI is high and often the infections tend to become chronic with many episodes. UTI usually starts as a bladder infection but often evolves to encompass the kidneys and ultimately can result in renal failure and may disseminate to the blood. Catheter-associated UTI accounts for $40 \%$ of all nosocomial infections and is the most common source of Gramnegative bacteraemia in hospitalized patients. Most

Abbreviations: SEM, scanning electron microscopy; TEM, transmission electron microscopy; UPEC, uropathogenic Escherichia coli; UTI, urinary tract infection.

A supplementary table of primers is available with the online version of this paper. patients with an indwelling urinary catheter for 30 days or longer develop bacteriuria (Stamm, 1991).

Uropathogenic Escherichia coli (UPEC) is the cause of the majority $(>80 \%)$ of UTIs in humans. UPEC isolates exhibit a high degree of genetic diversity due to the possession of specialized virulence genes located on mobile genetic elements called pathogenicity islands (Oelschlaeger et al., $2002 \mathrm{~b}$ ). Although no single virulence factor is uniquely definitive of UPEC, their ability to cause symptomatic UTI is enhanced by adhesins (e.g. type 1 and $\mathrm{P}$ fimbriae) and toxins (e.g. haemolysin) (Klemm \& Schembri, 2000; Oelschlaeger et al., 2002a). Adherence to the urinary tract epithelium is the first stage of UTI, enabling the bacteria to resist the hydrodynamic forces of urine flow and establish infection. Among the more common adhesins produced by UPEC are type 1, P, F1C, S and Auf fimbriae and the Afa/Dr adhesins (Oelschlaeger et al., 2002a).

Fimbrial adhesins of UPEC are characterized by a conserved chaperone-usher pathway that underpins their assembly (Sauer et al., 2004). Fimbriae assembled by the chaperone-usher pathway are typically encoded by 
individual gene clusters that in addition to the chaperoneand usher-encoding genes also include genes encoding the major and minor pilin subunits. $\mathrm{P}$ and type 1 fimbriae are the best-characterized chaperone-usher class of fimbriae produced by UPEC. P fimbriae are most strongly associated with UTI in clinical studies. P fimbriae contribute to the establishment of bacteriuria by binding to the $\alpha$-D-galactopyranosyl-(1-4)- $\beta$-D-galactopyranoside receptor epitope in the globoseries of glycolipids (Kallenius et al., 1981; Leffler \& Svanborg-Eden, 1981) and activate innate immune responses in animal models and in human infection (Svanborg et al., 2006). Similarly, type 1 fimbriae enhance colonization and stimulate immune responses in the murine urinary tract (Connell et al., 1996). Type 1 fimbriae confer binding to $\alpha$-D-mannosylated proteins such as uroplakins, which are abundant in the uroepithelial lining of the bladder (Wu et al., 1996). Both $P$ and type 1 fimbriae recognize their receptor targets by virtue of organelle tip-located adhesins, namely PapG and FimH, respectively (Klemm \& Schembri, 2000). F1C (Foc) are a third type of fimbriae that belong to the chaperone-usher subfamily and resemble type 1 fimbriae in their genetic organization and organelle structure (Klemm et al., 1994, 1995; van Die et al., 1991). F1C fimbriae mediate binding to galactosylceramide targets present on epithelial cells in the bladder and kidneys as well as globotriaosylceramide, present exclusively in the kidneys (Bäckhed et al., 2002; Khan et al., 2000). Other fimbriae of the chaperone-usher family that have been characterized from UPEC include $S$ fimbriae, which mediate adherence to sialic acid glycolipids or glycoproteins, and Auf fimbriae (Buckles et al., 2004; Korhonen et al., 1984).
Despite the vast array of adhesins that have been defined in UPEC, three recently sequenced UPEC genomes have revealed the existence of several additional gene clusters that display homology to genes from the chaperone-usher class of fimbriae (Brzuszkiewicz et al., 2006; Chen et al., 2006; Welch et al., 2002). For example, the genome sequence of UPEC CFT073 contains ten different loci that may encode fimbriae that belong to this subfamily. Only half of these fimbrial gene clusters have been characterized to date and the functions of the remainder are unknown. Here we identify and characterize one of these fimbrial gene clusters (c1931-c1936) from UPEC CFT073. The fimbriae encoded by this gene cluster, termed F9 fimbriae, are homologous to type 1 and $\mathrm{F} 1 \mathrm{C}$ fimbriae and promote biofilm formation on abiotic surfaces.

\section{METHODS}

Bacterial strains, plasmids and growth conditions. The strains and plasmids used in this study are described in Table 1. E. coli CFT073 was isolated from the blood and urine of a woman with acute pyelonephritis (Mobley et al., 1990). The E. coli Reference (ECOR) collection was obtained from the STEC Center, Michigan State University. Cells were routinely grown at $37^{\circ} \mathrm{C}$ on solid or in liquid Luria-Bertani (LB) medium supplemented with appropriate antibiotics unless otherwise stated. M9 minimal medium consisted of $42 \mathrm{mM} \mathrm{Na}_{2} \mathrm{HPO}_{4}, 22 \mathrm{mM} \mathrm{KH}_{2} \mathrm{PO}_{4}, 9 \mathrm{mM} \mathrm{NaCl}, 18 \mathrm{mM} \mathrm{NH}_{4} \mathrm{Cl}$, $1 \mathrm{mM} \mathrm{MgSO}, 0.1 \mathrm{mM} \mathrm{CaCl}_{2}$ and $0.2 \%$ glucose (Sambrook et al., 1989), supplemented with $0.2 \%$ arabinose and antibiotics where appropriate. For flow chamber biofilm experiments, the glucose concentration was reduced to $0.002 \%$.

Table 1. Bacterial strains and plasmids used in this study

\begin{tabular}{|c|c|c|}
\hline Strain or plasmid & Relevant characteristic(s) & Reference \\
\hline \multicolumn{3}{|l|}{ E. coli strains } \\
\hline CFT073 & UPEC reference strain & Mobley et al. (1990) \\
\hline MG1655 & K-12 reference strain & Bachmann (1996) \\
\hline MS428 & MG1655 fim & Kjaergaard et al. (2000b) \\
\hline MS673 & pBAD/Myc-HisA in MS428 & This study \\
\hline MS1129 & $\mathrm{pKC} 2$ in $\mathrm{MS} 428$ & This study \\
\hline MS1417 & CFT073 fim & This study \\
\hline MS1418 & CFT073 f9 : : kan & This study \\
\hline MS1432 & CFT073 fim foc : : kan & This study \\
\hline MS1433 & CFT073 fim foc & This study \\
\hline MS1436 & CFT073 fim foc f9: : kan & This study \\
\hline PK1097 & CFT073 fim : : kan & Roos et al. (2006b) \\
\hline \multicolumn{3}{|l|}{ Plasmids } \\
\hline pGB2-24 & fimH gene in pACYC184 & Sokurenko et al. (1994) \\
\hline pKD4 & Template plasmid for kan gene amplification & Datsenko \& Wanner (2000) \\
\hline pKD46 & $\lambda$-Red recombinase expression plasmid & Datsenko \& Wanner (2000) \\
\hline pCP20 & FLP synthesis under thermal control & Cherepanov \& Wackernagel (1995) \\
\hline pKC1 & c1934-c1936 genes in $\mathrm{pBAD} / \mathrm{Myc}$-HisA & This study \\
\hline $\mathrm{pKC} 2$ & F9 gene cluster in $\mathrm{pBAD} / \mathrm{Myc}$-HisA & This study \\
\hline pPKL52 & fimFGH genes in pBR322 & Klemm \& Christiansen (1987) \\
\hline
\end{tabular}


DNA manipulations and genetic techniques. Plasmid DNA was isolated using the QIAprep Spin Miniprep kit (Qiagen). Restriction endonucleases were used according to the manufacturer's specifications (New England Biolabs). Chromosomal DNA was purified using the GenomicPrep Cell and Tissue DNA isolation kit (Amersham Pharmacia Biotech). PCR was performed using the Expand Long Template PCR system (for amplification of the $f 9$ gene cluster) or Taq polymerase (screening assays) according to the manufacturer's instructions (Roche). The primers used in this study are shown in supplementary Table S1, available with the online version of this paper. DNA sequencing was performed by the Australian Genome Research Facility.

\section{Cloning of the F9 fimbriae-encoding gene cluster and PCR} screening assay. The F9 fimbriae-encoding gene cluster (c1931c1936) was amplified by PCR using primers 598 and 599. The PCR product was digested with $\mathrm{XhoI}$ and ligated to XhoI-digested plasmid $\mathrm{pBAD} / \mathrm{Myc}$-HisA (Invitrogen Life Technologies). In this construct, expression of the F9-encoding genes is under control of the arabinose-inducible araBAD promoter (Guzman et al., 1995). Specific primers were employed to screen for the prevalence of the F9 chaperone(596 and 597) and adhesin- (100 and 101) encoding genes.

\section{Construction of CFT073fim, CFT073fim foc and CFT073fim foc} f9 deletion mutants. CFT073 deletion mutants were constructed using the $\lambda$-Red recombinase gene replacement system (Datsenko \& Wanner, 2000). Briefly, the kanamycin resistance gene from plasmid pKD4 was amplified using primers containing 40-50 nt homology extensions to the start and end of the gene clusters to be deleted. The following primers were used: (i) 244 and 245 for deletion of the fim gene cluster; (ii) 495 and 496 for deletion of the foc gene cluster; (iii) 195 and 196 for deletion of the $f 9$ gene cluster. The primers were used to amplify a $1.6 \mathrm{~kb}$ PCR product from plasmid pKD4, representing the kanamycin resistance cassette from pKD4 and additional 40-50 bp overhang regions (underlined in Table S1) at the $5^{\prime}$ and $3^{\prime}$ ends of the PCR product complementary to the target genes in CFT073. CFT073 fim was constructed by transforming CFT073(pKD46) with the PCR product containing homology to the fim gene cluster and selection of kanamycin-resistant colonies. The kanamycin resistance cassette was then removed using plasmid pCP20. The foc deletion was constructed in a similar manner using CFT073fim(pKD46) to generate CFT073fim foc. This strain was subsequently used to generate CFT073fim foc $f 9$ by the same procedure, except that in this case the kanamycin resistance cassette was not removed. All deletions were confirmed by PCR using $\mathrm{k} 2$ and kt primers (Datsenko \& Wanner, 2000) in combination with 254 and 255 (fim deletion), 573 and 574 ( $f o c$ deletion) and 252 and 253 ( $f 9$ deletion) and subsequent DNA sequencing.

Agglutination and adherence assays. The capacity of F9expressing E. coli MS1129 to agglutinate human, dog, horse or sheep red blood cells (RBC), or yeast cells, was assessed as previously described (Roos et al., 2006a; Schembri et al., 2000). Briefly, a suspension of washed bacterial cells $\left(\mathrm{OD}_{550} 0.5\right)$ was mixed with RBC or yeast cells on a glass slide and the time to agglutination was measured. Adherence of MS1129 to human HeLa epithelial cells was determined essentially as previously described (Ulett et al., 2003).

Biofilm assays. Biofilm formation was monitored by using sterile non-treated 96-well round-bottom polystyrene microtitre plates (BD Falcon) essentially as previously described (Schembri \& Klemm, 2001). Briefly, cells were grown for $24 \mathrm{~h}$ in M9 minimal medium (containing $0.2 \%$ arabinose for induction of F9-encoding genes) at $37{ }^{\circ} \mathrm{C}$, washed to remove unbound cells and stained with crystal violet. Quantification of bound cells was performed by addition of acetone/ethanol $(20: 80, \mathrm{v} / \mathrm{v})$ and measurement of the dissolved crystal violet as absorbance at $595 \mathrm{~nm}$. Flow chamber experiments were performed essentially as previously described (Kjaergaard et al., 2000b; Schembri et al., 2003), with the exception that cells were detected using BacLight green fluorescent stain (Molecular Probes). Briefly, biofilms were allowed to form on glass surfaces in a multi-channel flow system that permitted online monitoring of community structures. Flow cells were inoculated with $\mathrm{OD}_{600}$ standardized cultures pre-grown overnight in M9 medium. Glucose was used as the sole carbon source at a concentration of $0.002 \%$ and BacLight green fluorescent stain was used at a concentration of $0.1 \mu \mathrm{M}$ according to the manufacturer's instructions. F9 expression was induced with $0.2 \%$ arabinose. Biofilm development was monitored by confocal scanning laser microscopy at $15 \mathrm{~h}$ after inoculation. All experiments were performed in triplicate. Biofilms analysed by scanning electron microscopy (SEM) were grown in 24-well cell culture plates on $15 \mathrm{~mm}$ sterile Thermanox plastic coverslip inserts (Nalgene Nunc International). Wells containing coverslip inserts were seeded with approximately $10^{4}$ c.f.u. resuspended in $1 \mathrm{ml} \mathrm{M} 9$ medium and were incubated statically overnight at $37{ }^{\circ} \mathrm{C}$. Coverslips were removed from the wells after $24 \mathrm{~h}$, washed extensively with PBS and incubated in fresh medium for a further $24 \mathrm{~h}$ to allow biofilm maturation prior to processing for SEM analysis.

RNA isolation and RT-PCR. UPEC CFT073 was grown to exponential phase in M9 minimal medium and resuspended directly in an equal volume of ice-cold RNAlater (Ambion). Total RNA was isolated using an RNeasy mini kit (Qiagen). RNA was treated with RNase-free DNase, repurified and stored at $-80{ }^{\circ} \mathrm{C}$. RNA was converted to cDNA using SuperScript II as described by the manufacturer (Invitrogen Life Technologies). A negative control of non-reversetranscribed RNA was used to confirm the absence of contaminating genomic DNA. RT-PCR was performed for 25 cycles $\left(94{ }^{\circ} \mathrm{C} 15 \mathrm{~s}\right.$, $50{ }^{\circ} \mathrm{C} 15 \mathrm{~s}, 72{ }^{\circ} \mathrm{C} 1 \mathrm{~min}$ ) with primers 600 and 601 . These primers were specific for F9 major subunit-encoding gene (c1936) and did not amplify the closely related fimA or focA genes.

Purification of F9 fimbriae and antibody production. A $500 \mathrm{ml}$ culture of MS1129 cells was grown in $\mathrm{LB}$ to an $\mathrm{OD}_{600}$ of 1.0 , induced for F9 fimbriae expression for $2 \mathrm{~h}$ with $0.2 \%$ arabinose, harvested by centrifugation and resuspended in $10 \mathrm{ml}$ PBS. Fimbriae were detached from the cells with a mini hand blender using five $30 \mathrm{~s}$ pulses essentially as previously described (Klemm et al., 1998). The bacteria were pelleted and the detached F9 fimbriae present in the supernatant were precipitated with 4 vols ice-cold acetone. Proteins were collected by centrifugation, resuspended in PBS and stored at $-80{ }^{\circ} \mathrm{C}$ until required. Fimbriae were prepared for SDS-PAGE analysis by boiling in acid ( $\mathrm{pH} 2.0$ adjusted by the addition of $2.0 \mathrm{M} \mathrm{HCl}$ ) for $3 \mathrm{~min}$. The preparation was then readjusted to $\mathrm{pH} 7.0$ by the addition of $2.0 \mathrm{M}$ $\mathrm{NaOH}$ and boiled for a further 3 min. SDS-PAGE analysis was performed as previously described (Ulett et al., 2006). Polyclonal antiF9 antiserum was raised in New Zealand White rabbits by intramuscular immunization as described elsewhere (Lam \& Mutharia, 1994). The primary immunization dose was $200 \mu \mathrm{g}$ in $0.5 \mathrm{ml}$ Freund's Adjuvant Complete (Sigma)/PBS (1: 1, v/v) followed by three booster doses at 2 week intervals using $200 \mu \mathrm{g}$ in $0.5 \mathrm{ml}$ Freund's Adjuvant Incomplete (Sigma)/PBS (1:1, v/v).

Electron microscopy. Cells for transmission electron microscopy (TEM) were prepared from freshly grown colonies or liquid suspensions resuspended in a drop of sterile ultra-pure water. A glow-discharged Formvar-coated copper grid was placed on the drop for $1 \mathrm{~min}$ to allow the cells to adsorb. Excess liquid was removed with filter paper before a drop of $1 \%$ ammonium molybdate (negative stain) was placed on the grid. For immunoelectron microscopy bacteria were adsorbed onto glow-discharged carbon-coated copper grids for $5 \mathrm{~min}$. Grids were placed on two drops of PBS (2 min) followed by $5 \mathrm{~min}$ on blocking buffer (PBS containing $0.2 \%$ BSA, $0.2 \%$ fish skin gelatin, $20 \mathrm{mM}$ glycine). Samples were reacted with anti-F9 serum (1: 100 diluted in blocking buffer) for $30 \mathrm{~min}$ and 
washed four times in blocking buffer $(5 \mathrm{~min})$. Samples were then incubated with anti-rabbit IgG gold conjugate $(10 \mathrm{~nm}$ diameter, diluted 1:60 in blocking buffer) for $30 \mathrm{~min}$ and washed four times ( $5 \mathrm{~min}$ ) in PBS followed by four washes $(2 \mathrm{~min}$ ) in water. Some grids were dried and observed unstained while others were negatively stained with $1 \%$ ammonium molybdate. Cells were examined under a JEOL JEM1010 TEM operated at $80 \mathrm{kV}$. Images were captured using an analySIS Megaview III digital camera. SEM was performed essentially as previously described (Webster et al., 2004).

\section{RESULTS}

\section{Identification of the F9 fimbriae-encoding gene cluster from UPEC CFT073}

The UPEC strain CFT073 genome contains ten gene loci that share sequence identity with the chaperone-usher class of fimbriae (Table 2). Five of these gene clusters have been characterized to date. In this study, we chose to focus on the putative fimbrial gene cluster $c 1931-c 1936$, which encodes F9 fimbriae recently described from E. coli O157 : H7 (Low et al., 2006a). The F9 gene cluster contains six open reading frames arranged in the same transcriptional orientation (Fig. 1A). The F9 gene cluster is flanked by two genes ( $y$ deP and hipA) which are conserved in both the CFT073 and MG1655 genomes. However, part of the F9 gene cluster has been deleted in MG1655 (Fig. 1A). The F9 gene cluster is similar to other fimbrial operons of the chaperone-usher class in that it contains genes encoding putative major (c1936) and minor subunit proteins $(c 1932, c 1933)$ as well as putative chaperone- (c1935), usher- (c1934) and adhesin(c1931) encoding genes. The overall $\mathrm{G}+\mathrm{C}$ content of the F9 gene cluster is $44.4 \mathrm{~mol} \%$. This is significantly lower than that normally found in E. coli (50.8 $\mathrm{mol} \%)$ and suggests that the genes may have been acquired by horizontal transfer.

\section{Cloning and expression of the F9 fimbriae- encoding gene cluster}

The F9 gene cluster was amplified by PCR from UPEC CFT073 and cloned as a transcriptional fusion behind the tightly regulated araBAD promoter in the $\mathrm{pBAD} / \mathrm{Myc}$ HisA expression vector to generate plasmid $\mathrm{pKC} 2$. To determine if the F9 gene cluster encodes the capacity to produce fimbriae we transformed E. coli MS428 with pKC2 to create MS1129. E. coli MS428 contains a deletion in the type 1 fimbrial gene locus and therefore does not produce any fimbriae (Kjaergaard et al., 2000b). When MS1129 cells were induced with $0.2 \%$ arabinose we observed $0.2-2 \mu \mathrm{m}$ long fimbrial organelles on the bacterial cell surface by TEM (Fig. 1C). The fimbriae were purified and examined by SDS-PAGE. A major protein of approximately $15 \mathrm{kDa}$ was obtained (Fig. 1B) and this preparation was used to raise an anti-F9 polyclonal antiserum in rabbits. Immunogold electron microscopy with this antiserum reacted strongly against MS1129 cells induced for F9 fimbriae expression (Fig. 1D). Thus, the F9 gene cluster is functional and its expression results in the production of fimbriae in a defined K-12 host background.

\section{Agglutination and adherence properties of F9 fimbriae}

The agglutination of erythrocytes is the classical assay for monitoring interactions between fimbrial adhesins and species-specific glycoproteins. MS1129 cells induced for F9 expression did not agglutinate erythrocytes from humans, dog, horse or sheep. Since the F9 genes display strong similarity to type 1 fimbrial genes we also tested their ability to agglutinate yeast cells. Yeast cell agglutination is the most highly conserved binding property for type 1 fimbriae. However, MS1129 cells were also unable to agglutinate yeast cells, indicating that unlike its FimH counterpart, the putative F9 adhesin does not bind to Dmannose. Arabinose-induced MS1129 cells were also unable to bind to human HeLa epithelial cells.

\section{F9 fimbriae mediate biofilm formation}

MS1129 cells were tested for their ability to form biofilms in standard microtitre plate assays as well as a continuousflow chamber system. F9 fimbriae mediated strong biofilm formation in the hydrodynamic microtitre plate assay after growth in M9 medium (Fig. 2A). Interestingly, we did not

Table 2. Fimbriae-encoding genes in CFT073

\begin{tabular}{|c|c|c|c|}
\hline Description & c number & Genes & Receptor target \\
\hline Putative chaperone-usher fimbrial operon & c0166-c0172 & yadN-ecpD-htrE-yadMLKC & Unknown \\
\hline F1C & c1237-c1245 & $s f a C B$ focAICDFGH & Galactosylceramide \\
\hline F9 & c1931-c1936 & c1936-34-ydeSRQ & Unknown \\
\hline Putative chaperone-usher fimbrial operon & $c 2635-c 2638$ & yeh $A B C D$ & Unknown \\
\hline Putative chaperone-usher fimbrial operon & $c 2878-c 2884$ & $y f c O P Q R S U V$ & Unknown \\
\hline P fimbriae & c3583-c3593 & papIBAHCDJKEFG & $\alpha$-D-Gal-(1-4)- $\beta$-D-Gal \\
\hline Putative chaperone-usher fimbrial operon & c3791-c3794 & ygiLGH-c3794 & Unknown \\
\hline Auf fimbriae & $c 4207-c 4214$ & aufABCDEFG & Unknown \\
\hline P fimbriae (2) & c5179-c5189 & papIBAHCDJKEFG & $\alpha$-D-Gal-(1-4)- $\beta$-D-Gal \\
\hline Type 1 fimbriae & c5391-c5399 & fimBEAICDFGH & D-Mannose \\
\hline
\end{tabular}



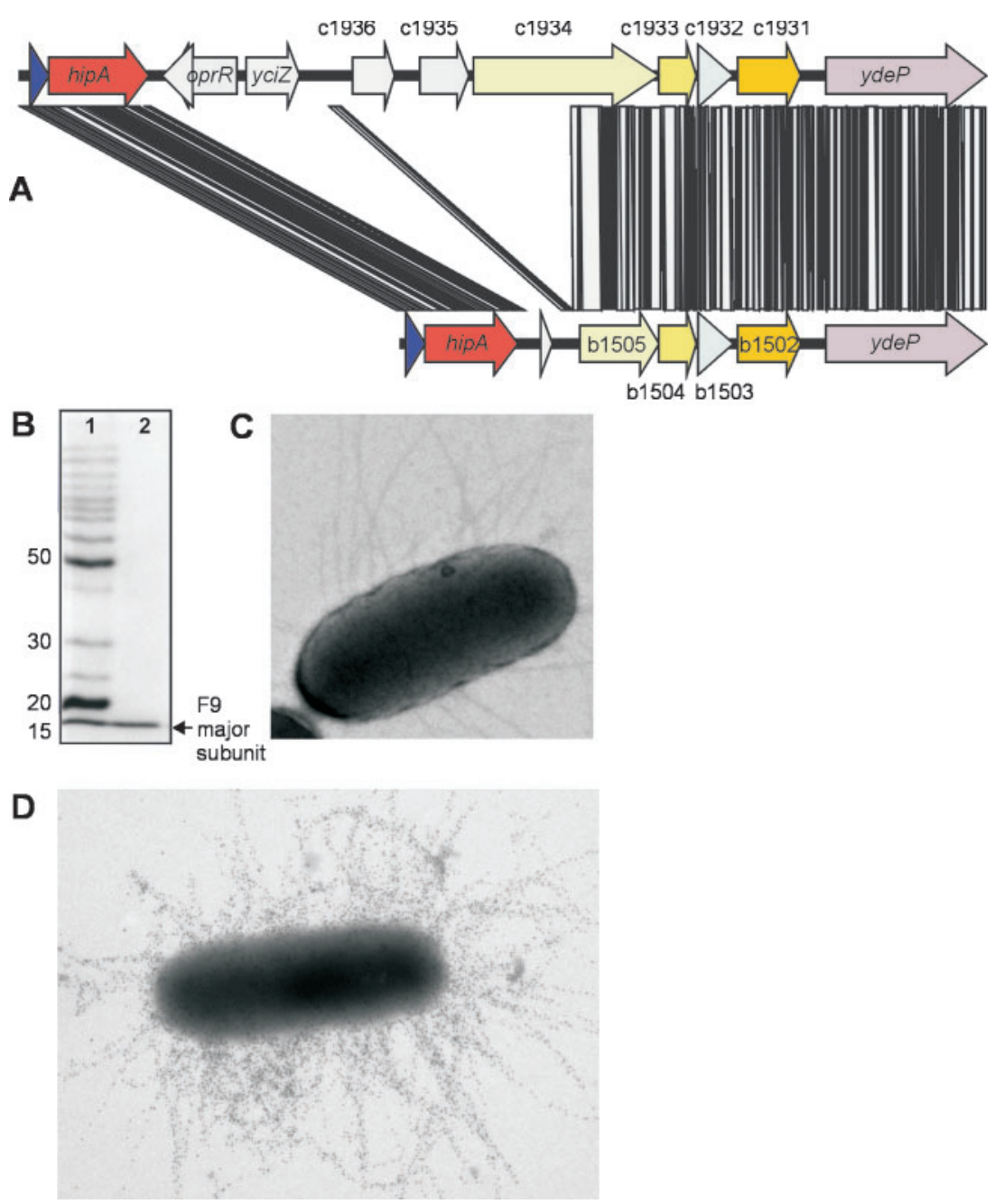

Fig. 1. (A) Physical map of the F9 gene cluster from E. coli CFT073 indicating the arrangement of the genes (including adjacent genes). A comparison of the CFT073 F9 gene cluster is shown together with the corresponding gene cluster in MG1655. Highly homologous regions are shaded black. The F9 genes are indicated by their $\mathrm{c}$ number and are predicted to encode the following proteins: c1936, major subunit; c1935, chaperone; c1934, usher; c1933, minor subunit; c1932, minor subunit; c1931, adhesin. (B) Coomassie blue stain of F9 fimbriae purified from $E$. coli MS1129 and separated on a 15\% SDSPAGE gel. (C) Transmission and (D) immunogold electron microscopy demonstrating expression of F9 fimbriae in recombinant $E$. coli K-12 MS1129. F9 fimbrial expression was induced in MS1129 by the addition of arabinose. Immunogold labelling was performed with an F9-specific antiserum. observe any biofilm formation when the same experiment was performed using LB medium (data not shown). SEM of the biofilms confirmed these results (Fig. 2B). No significant biofilm was formed by the E. coli MS673 vector control strain (Fig. 2C). The ability of F9 fimbriae to promote biofilm formation in dynamic conditions was examined using a continuous-flow chamber system. F9expressing cells produced a dense and uniform biofilm that covered the entire surface of the flow cell with an average depth of $20 \mu \mathrm{m}$ (Fig. 2D). Taken together, these data demonstrate that F9 fimbriae mediate strong biofilm formation in $E$. coli $\mathrm{K}-12$ cells employing two different model systems.

\section{Analysis of F9 fimbriae expression by UPEC CFT073}

In order to determine whether the F9 genes are expressed by wild-type UPEC CFT073, transcription of the F9 major subunit-encoding gene (c1936) was analysed by RT-PCR. RNA was extracted from exponentially growing cells, converted to cDNA and a PCR was performed using c1936-specific primers. We detected a c1936 transcript from cells grown in minimal medium (Fig. 3). No PCR products were obtained from RNA samples prior to cDNA synthesis. These results demonstrate that the c1936 gene in CFT073 is transcribed during exponential growth in M9 minimal medium. However, despite these results, we were unable to detect expression of the corresponding protein by Western blotting using F9-specific antiserum on crude lysates of CFT073 grown under the same conditions.

In E. coli, the expression of some types of fimbriae is enhanced under aerated static liquid growth conditions (Old \& Duguid, 1970; Stentebjerg-Olesen et al., 2000). Static growth results in the formation of a pellicle at the air-liquid interface that can be promoted by either type 1 or F1C fimbriae (Snyder et al., 2005). Before attempting to induce F9 expression in CFT073 by static growth we therefore deleted the type 1- and F1C-encoding fimbrial genes in CFT073 by $\lambda$-Red recombination of linear DNA (Datsenko \& Wanner, 2000). The correct deletions were confirmed by PCR and sequencing of the resultant strain (Fig. 4A, B), which was designated CFT073fim foc. To determine if CFT073fim foc could produce a pellicle at the 

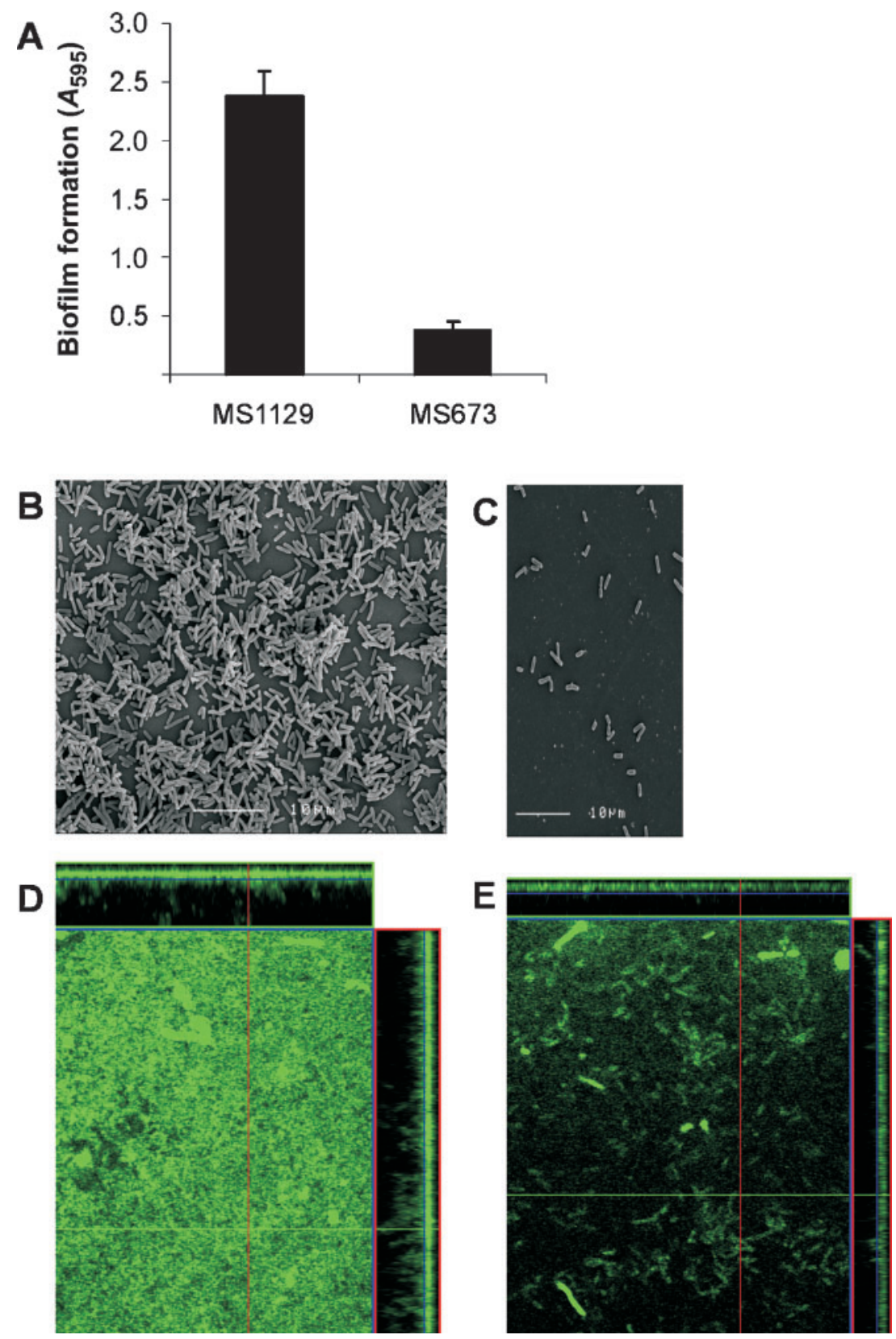

Fig. 2. Biofilm formation by E. coli MS1129 in the microtitre plate assay. (A) MS1129 cultures were grown overnight in M9 minimal medium containing $0.2 \%$ arabinose, washed to remove unbound cells and stained with crystal violet to measure biofilm formation (plotted as mean \pm SD of three independent determinations). Significantly increased biofilm formation by the F9-induced MS1129 cells in comparison to MS673 vector control cells is demonstrated. $(B, C)$ Similar experiments were also performed using biofilms grown on plastic coverslip inserts in 24-well plates. SEM of these cells was used to visualize the biofilm produced by MS1129 cells (B) and MS673 control cells (C). (D, E) Flow chamber biofilm formation of (D) E. coli MS1129 (F9 positive) and (E) E. coli MS673 (vector control) cells. Biofilm development was monitored by confocal scanning laser microscopy $15 \mathrm{~h}$ after inoculation. Micrographs represent horizontal sections. Depicted to the right and below are vertical sections through the biofilm collected at the positions indicated by the lines.

air-liquid interface it was grown under static culture conditions for $72 \mathrm{~h}$. A sample from the air-liquid interface was then removed and used to inoculate a second culture. After three successive rounds of selection and enrichment for pellicle growth, the CFT073fim foc mutant produced a thick pellicle. These cells were then collected, blended to remove any fimbriae and the proteins present in the supernatant were precipitated with acetone. When assessed by SDS-PAGE one prominent band $(\sim 18 \mathrm{kDa})$ as well as a minor band $(\sim 16 \mathrm{kDa})$ was observed (Fig. $4 \mathrm{C})$. These protein sizes correlate with the predicted size of major subunit proteins from many fimbriae of the chaperoneusher class. Western blotting employing our F9-specific antiserum demonstrated the presence of the major F9 subunit as part of the weaker band (Fig. 4D). We also attempted to identify these proteins by $\mathrm{N}$-terminal sequence analysis. The predominant band $(\sim 18 \mathrm{kDa})$ was confirmed to be the PapA2 major subunit protein of $\mathrm{P}$ fimbriae. We also identified the PapA protein as part of the minor band. However, we were unable to conclusively detect the F9 major subunit protein sequence as a minor component from the background trace of this $\mathrm{N}$-terminal sequence; the background trace was at $10 \%$ of the overall signal intensity. We also note that in experiments with plasmid-encoded pap gene clusters we did not observe any cross-reaction between our F9-specific antiserum and $\mathrm{P}$ 


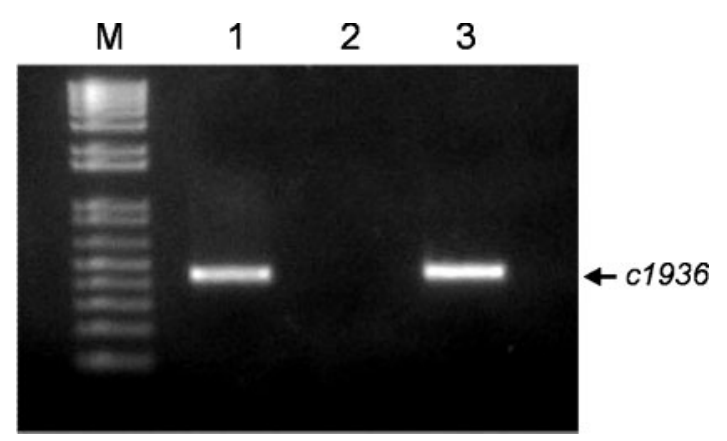

Fig. 3. RT-PCR analysis of c1936 expression by CFT073. Total RNA was extracted from CFT073 during exponential growth in M9 minimal medium. Lanes: 1, c1936-specific PCR product (450 bp) obtained using cDNA as the template; 2, negative control using RNA prior to cDNA synthesis; 3, positive control using CFT073 genomic DNA as the template; M, 1-kb Plus DNA Ladder (Invitrogen).

fimbriae (data not shown). To confirm that the positive reaction in the Western blot was due to the presence of F9 fimbriae, we deleted the F9 genes from CFT073fim foc to construct CFT073fim foc f9. This strain produced a thick pellicle after three successive rounds of selection and enrichment by static growth. However, when the fimbriae of pellicle-enriched CFT073fim foc $f 9$ were purified and probed by Western blot analysis using the F9 antiserum, no reaction was observed (Fig. 4D). Taken together, these results demonstrate that the F9 major subunit-encoding gene (c1936) is transcribed in CFT073 and that F9 expression can be induced by static growth in a CFT073fim foc background, albeit at very low levels. However, under these growth conditions, $\mathrm{P}$ fimbriae are the major fimbriae induced in the CFT073fim foc mutant.

\section{Biofilm formation by CFT073 wild-type and fimbrial deletion mutants}

To test the ability of CFT073, CFT073f9, CFT073fim, CFT073fim foc and CFT073fim foc $f 9$ to form a biofilm we employed both static and dynamic biofilm assays. The strains were grown in M9 minimal medium and biofilm formation was assessed using sterile non-treated polystyrene microtitre plates. There was no difference in biofilm formation between any of the strains under either of the two conditions (Fig. 5). These results are consistent with our observations of a very low level of F9 expression in CFT073.

\section{The FimH adhesin cannot be incorporated into the F9 structural organelle}

Previous studies have demonstrated that reciprocal exchange of components between type 1 and F1C fimbriae can result in the expression of functional chimeric organelles (Klemm et al., 1994; Sokurenko et al., 2001). Given the strong similarity between the F9 and type 1 fimbrial proteins (Table 3), we attempted to exchange the minor components of the fim system with those of the F9 system. The F9 gene cluster was truncated by removal of the region encoding c1931-c1933 to generate plasmid pKC1 (containing c1934-c1936). E. coli MS428 cells harbouring $\mathrm{pKCl}$ were then transformed with a plasmid containing the fimFGH genes (pPKL52). When these cells were mixed with yeast cells no agglutination occurred, indicating that the FimH adhesin was not incorporated
A $\underset{f i m B}{ }$

GATTGAGGATTTCGGATATTATCTTAAGGCAAAGTGGTGTAGGCTGGAGCTGCTTCGAAGTTCCTATACT TTCTAGAGAATAGGAACTTCGGAATAGGAACTAAGGAGGATATTCATATGTACGATTATTCCAGCGAATA ACACGGTATCGTTAGG

fimH

B focA

CATCTCCATGGCTGTATTTTCAGCTCTGACCCTGGGGTGTAGGCTGGAGTTGCTTCGAAGTTCCTATACT TTTTAGAGAATAGGAACTTCGGAATAGGAACTAAGGAGGATATTCATATGATGTACCTTTATCCTGAGCC GGGCGTTTTCGGGAAA.

focH
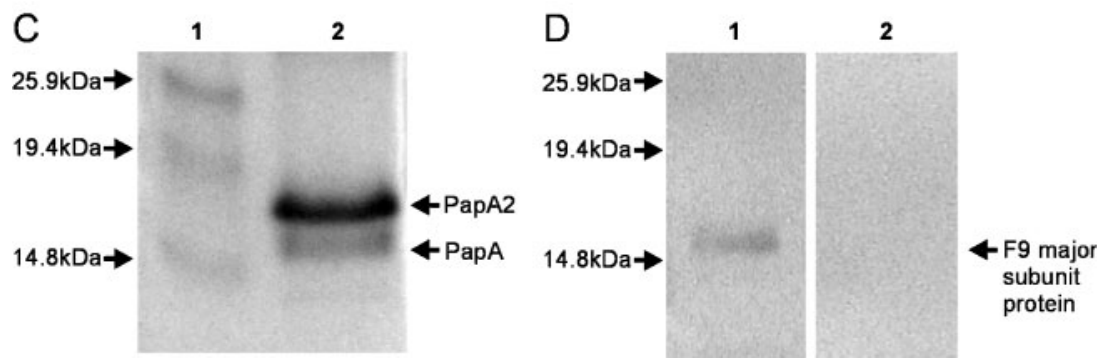

Fig. 4. (A) DNA sequence of the type 1 fimbrial (fim) deletion in CFT073fim foc; the fim $B$ and $f i m H$ sequences are highlighted and the $84 \mathrm{bp}$ scar is also shown. (B) DNA sequence of the $\mathrm{F} 1 \mathrm{C}(f \circ c)$ fimbrial deletion in CFT073fim foc; the focH and foc $A$ sequences are highlighted and the $84 \mathrm{bp}$ scar is also shown. (C) SDS-PAGE analysis of purified fimbrial proteins from the CFT073fim foc pellicle. The major and minor bands were identified by $\mathrm{N}$-terminal amino acid sequencing as PapA2 and PapA, respectively (lane 2). Molecular size markers are indicated (lane 1). (D) Western blot of purified fimbrial proteins from CFT073fim foc (lane 1) and CFT073fim foc f9 (lane 2) reacted with F9-specific antiserum. The F9 major subunit protein was only observed in fimbrial preparations from CFT073fim foc (lane 1). 


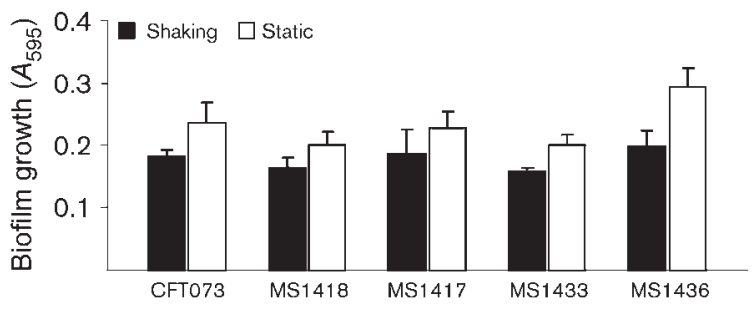

Fig. 5. Biofilm formation by CFT073, MS1418 (CFT073f9), MS1417 (CFT073fim), MS1433 (CFT073fim foc) and MS1436 (CFT073fim foc f9) strains. Biofilm formation was examined in polystyrene microtitre plates using static and dynamic growth conditions. Cells were grown at $37{ }^{\circ} \mathrm{C}$ for $24 \mathrm{~h}$ in $\mathrm{M} 9$ minimal medium supplemented with $0.2 \%$ glucose. Adhered cells were stained with crystal violet. The quantification of results after the determination of $A_{595}$ readings is shown as the mean \pm SD of three independent experiments.

into the F9 organelle. We also combined a plasmid encoding the entire F9 cluster ( $\mathrm{pKC}$ ) with a plasmid encoding the fimH gene alone (pGB2-24) or the fimFGHcontaining plasmid (pPKL52), in MS428. However, both of these strains also failed to agglutinate yeast cells. Taken together, these results indicate that although the type 1 and F9 genes display a high degree of sequence conservation, the minor components (FimF, FimG) and adhesin (FimH) of type 1 fimbriae cannot be incorporated into the F9 fimbrial organelle.

\section{Prevalence of F9 fimbriae-encoding genes in other E. coli}

We screened 20 UPEC isolates from our laboratory collection as well as the 72 strains from the ECOR collection to determine the prevalence of the F9 gene cluster amongst a diverse population of $E$. coli isolates. Primers were designed from regions predicted to be highly conserved within the gene cluster, i.e. the putative chaperone- (c1935) and adhesin- (c1931) encoding genes. We found that the c1935

Table 3. Comparison of the F9 protein and nucleotide sequences with the corresponding Fim and Foc sequences

\begin{tabular}{|llll|}
\hline $\begin{array}{l}\text { F9 } \\
\text { protein }\end{array}$ & $\begin{array}{c}\text { Putative } \\
\text { function }\end{array}$ & $\begin{array}{c}\text { Amino acid identity } \\
\text { (and nucleotide sequence } \\
\text { conservation) to corresponding }\end{array}$ \\
\cline { 3 - 4 } & & Fim protein & Foc protein \\
\hline C1936 & Major subunit & $59 \%(59 \%)$ & $54 \%(54 \%)$ \\
C1935 & Chaperone & $56 \%(61 \%)$ & $60 \%(62 \%)$ \\
C1934 & Usher & $56 \%(62 \%)$ & $51 \%(56 \%)$ \\
C1933 & Minor subunit & $43 \%(54 \%)$ & $28 \%(48 \%)$ \\
C1932 & Minor subunit & $56 \%(61 \%)$ & $36 \%(51 \%)$ \\
C1931 & Adhesin & $46 \%(54 \%)$ & $32 \%(47 \%)$ \\
\hline
\end{tabular}

and $c 1931$ genes were present in $80 \%(16 / 20)$ of clinical isolates in our collection and $56 \%(40 / 72)$ of strains from the ECOR collection. E. coli K-12 MG1655 contains the c1931 gene and a truncated version of c1934 but does not contain $c 1935$ (Fig. 1A). The high frequency of both $c 1935$ and $c 1931$ in the UPEC isolates tested here suggests that the deletion found in the K-12 MG1655 strain is not representative of the clinical UPEC isolates in our collection. We also screened the strains in the ECOR collection for the expression of F9 fimbriae using slide agglutination reactions with our F9 antiserum. Ten positively reacting strains were identified (data not shown). However, these ten strains also reacted positively in yeast cell agglutination reactions, suggesting the possibility of cross-reaction between some FimA variants of type 1 fimbriae and our F9 antiserum. In this respect we note that our type 1 fimbriae antiserum (raised against purified type 1 fimbriae from MG1655) did not cross-react with F9 fimbriae produced by MS1129. The precise characterization of these strains with respect to this phenotype is in progress.

\section{DISCUSSION}

In order to establish infection in the urinary tract UPEC must be able to adhere to host cells and avoid elimination. Virtually all E. coli strains are able to express adhesins in the form of fimbriae, long thread-like surface organelles that enable bacteria to recognize and attach to receptor molecules on specific host cell surfaces (Klemm \& Schembri, 2000). Most UPEC isolates are able to express several different adhesins that mediate specific binding to the uroepithelium with different receptor specificities. The most common fimbriae on UPEC are type 1 and $\mathrm{P}$ fimbriae, and $>80 \%$ of the strains are able to express either or both fimbrial types (Gander \& Thomas, 1987; Nowicki et al., 1984); 14-30\% are able to express F1C fimbriae (Pere et al., 1987). In the present study we have characterized F9 fimbriae from UPEC CFT073.

The genes encoding F9 fimbriae are highly similar to those of type 1 and F1C fimbriae (Table 3 ) and are arranged in a similar structural unit. A gene encoding a putative LysRfamily transcriptional regulatory protein ( $y c j Z)$ lies $1620 \mathrm{bp}$ upstream of c1936; however, at present there is no evidence to indicate that it plays a role in the regulation of F9 expression. The expression of other chaperone-usher class fimbriae in UPEC is phase variable, although the underlying regulatory systems are very different. Type 1 fimbriae expression is based on DNA inversion (Klemm, 1986), whereas phase variation of $\mathrm{P}$ fimbriae depends on a combination of Dam methylation and the PapB and PapI regulators (Braaten et al., 1994; Forsman et al., 1989). F1C and $\mathrm{S}$ fimbrial expression is thought to be similar to that of $\mathrm{P}$ fimbriae although the exact regulatory mechanisms involved remain to be elucidated. We did not find any evidence based on DNA sequence analysis that F9 expression could be phase variable. There are no recombinase-encoding genes 
upstream of the F9 genes and the nearest GATC site lies 558 bp upstream of the predicted F9 major subunit start site.

Among the genome-sequenced E. coli strains available on the NCBI database, several, including F11 (ExPEC), O42 (EAEC), B171 (EPEC), B7A (ETEC), E110019, E22, E2348/ 69 (EPEC), EDL933 and RIMD 0509952 (EHEC), contain an intact F9 gene cluster. The deletion encompassing c1934-c1936 in MG1655 is common to W3110 (K-12) and HS (commensal strain). The recently sequenced UPEC strain UTI89 contains a unique deletion in the F9 cluster, which includes part of c1932, c1933 and part of c1934. Taken together, these genome sequence data suggest that the intact F9 gene cluster is found in many types of E. coli. These data also correlate with our observation that the c1931 and c1935 genes were highly prevalent in our UTI clinical strains. Our PCR strategy of screening for the $c 1931$ and $c 1935$ genes would have successfully identified strains that contained the MG1655 deletion. However, the newly identified smaller deletion in UTI89 would not have been identified by this approach. Thus, a more detailed analysis of the F9 genes is required to accurately determine the prevalence of the intact gene cluster in UPEC.

Previous work has demonstrated that the expression of one fimbrial type can repress the expression of other fimbriae, suggesting there may be a hierarchical structure associated with coordinated fimbrial expression (Holden \& Gally, 2004). For example PapB, the regulator of $\mathrm{P}$ fimbrial expression, can repress the expression of type 1 fimbriae (Xia et al., 2000). Given the strong homology between type 1, F1C and F9 fimbriae, we deleted the type 1 and F1C fimbrial gene clusters in CFT073. Static growth of this strain (CFT073fim foc) induced the formation of a pellicle that consisted primarily of cells that produced P fimbriae derived from both pap gene clusters. To our knowledge, this is the first report to demonstrate that $\mathrm{P}$ fimbriae can promote pellicle growth. When the purified fimbriae present in the pellicle were tested by Western blotting a positive reaction was also obtained with our F9-specific antiserum, indicating the presence of the F9 major subunit protein. No F9 fimbriae were detected from pellicle preparations of the CFT073fim foc f9 triple mutant. Thus, although $\mathrm{P}$ fimbriae were the major fimbriae induced in CFT073fim foc static cultures, a low level of F9 fimbriae expression was also evident and made up a minor part of the total fimbriae purified from the cell pellicle.

UPEC are capable of forming biofilm-like structures within the superficial umbrella cells of the bladders of mice (Anderson et al., 2003). These structures are associated with the expression of type 1 fimbriae and Ag43 and are thought to promote persistence in the urinary bladder (Eto et al., 2006). In E. coli K-12, several cell-surface factors, including type 1 fimbriae (Kjaergaard et al., 2000a; Schembri \& Klemm, 2001; Schembri et al., 2003), flagella (Pratt \& Kolter, 1998), Ag43 (Kjaergaard et al., 2000a; Schembri et al., 2003) and curli (Vidal et al., 1998), have been implicated in biofilm formation. It is likely that many of these factors also contribute to catheter-associated UTIs caused by UPEC. Here we demonstrate that F9 fimbriae mediate strong biofilm growth in a recombinant E. coli strain. The environmental conditions that activate the expression of F9 fimbriae in wild-type UPEC remain to be determined. However, it is noteworthy that several studies have reported increased expression of F9 genes in a variety of $E$. coli pathotypes. A recent microarray study identified the F9 genes as being upregulated in CFT073 isolated directly from the urine of infected mice (Snyder et al., 2004). In E. coli $\mathrm{O} 157: \mathrm{H} 7$, the $\mathrm{F} 9$ gene cluster is analogous to the loc8 locus (Dziva et al., 2004; Low et al., 2006a). Expression of the F9 genes was analysed by chromosomally integrated lac $Z$ promoter fusions and shown to be enhanced during biofilm growth and during growth at $28{ }^{\circ} \mathrm{C}$ (as opposed to $37^{\circ} \mathrm{C}$ ) (Low et al., 2006b). Here we demonstrate that F9 fimbriae promote biofilm growth. Consistent with our findings, Low et al. (2006b) also did not find any evidence of phase variation from the F9 promoter. In other studies, the F9 genes have been reported to be important for the colonization of calves by E. coli O157 : $\mathrm{H} 7$ and O26 (Dziva et al., 2004; van Diemen et al., 2005) and F9 fimbriae were shown to mediate adherence to bovine epithelial cells (Low et al., 2006a). However, in contrast to the bundle-like arrangement of F9 fimbriae at the cell pole observed when the E. coli O157 : H7 F9 genes were expressed in E. coli K-12 (Low et al., 2006a), the F9 fimbriae produced by our recombinant strain MS1129 were arranged peritrichously on the cell surface, with a length varying between 0.2 and $2 \mu \mathrm{m}$. Furthermore, we did not observe a difference in the amount of F9 major subunit protein produced following static growth of the CFT073fim foc mutant at $28{ }^{\circ} \mathrm{C}$ and 37 ${ }^{\circ} \mathrm{C}$ (data not shown).

In summary, the genes encoding F9 fimbriae are commonly found in UPEC and other types of pathogenic E. coli. Several studies, including the present work, have now demonstrated expression of the F9 genes in E. coli (Dziva et al., 2004; Low et al., 2006a, b; Snyder et al., 2004; van Diemen et al., 2005). One function of F9 fimbriae is their ability to mediate strong biofilm growth. Further molecular characterization of the F9 genes is now required to investigate how their expression is regulated in relation to other fimbriae and to assess their function in wild-type E. coli.

\section{ACKNOWLEDGEMENTS}

This work was supported by grants from the Australian National Health and Medical Research Council (301163 and 455914).

\section{REFERENCES}

Anderson, G. G., Palermo, J. J., Schilling, J. D., Roth, R., Heuser, J. \& Hultgren, S. J. (2003). Intracellular bacterial biofilm-like pods in urinary tract infections. Science 301, 105-107. 
Bachmann, B. (1996). Derivations and genotypes of some mutant derivatives of Escherichia coli K-12. In Escherichia coli and Salmonella: Cellular and Molecular Biology, 2nd edn, pp. 2460-2488. Edited by F. C. Neidhardt and others. Washington, DC: American Society for Microbiology.

Bäckhed, F., Alsen, B., Roche, N., Angstrom, J., von Euler, A., Breimer, M. E., Westerlund-Wikstrom, B., Teneberg, S. \& RichterDahlfors, A. (2002). Identification of target tissue glycosphingolipid receptors for uropathogenic, F1C-fimbriated Escherichia coli and its role in mucosal inflammation. J Biol Chem 277, 18198-18205.

Braaten, B. A., Nou, X., Kaltenbach, L. S. \& Low, D. A. (1994). Methylation patterns in pap regulatory DNA control pyelonephritisassociated pili phase variation in E. coli. Cell 76, 577-588.

Brzuszkiewicz, E., Bruggemann, H., Liesegang, H., Emmerth, M., Olschlager, T., Nagy, G., Albermann, K., Wagner, C., Buchrieser, C. \& other authors (2006). How to become a uropathogen: comparative genomic analysis of extraintestinal pathogenic Escherichia coli strains. Proc Natl Acad Sci U S A 103, 12879-12884.

Buckles, E. L., Bahrani-Mougeot, F. K., Molina, A., Lockatell, C. V., Johnson, D. E., Drachenberg, C. B., Burland, V., Blattner, F. R. \& Donnenberg, M. S. (2004). Identification and characterization of a novel uropathogenic Escherichia coli-associated fimbrial gene cluster. Infect Immun 72, 3890-3901.

Chen, S. L., Hung, C. S., Xu, J., Reigstad, C. S., Magrini, V., Sabo, A., Blasiar, D., Bieri, T., Meyer, R. R. \& other authors (2006). Identification of genes subject to positive selection in uropathogenic strains of Escherichia coli: a comparative genomics approach. Proc Natl Acad Sci U S A 103, 5977-5982.

Cherepanov, P. P. \& Wackernagel, W. (1995). Gene disruption in Escherichia coli: TcR and $\mathrm{KmR}$ cassettes with the option of Flpcatalyzed excision of the antibiotic-resistance determinant. Gene 158, 9-14.

Connell, I., Agace, W., Klemm, P., Schembri, M., Marild, S. \& Svanborg, C. (1996). Type 1 fimbrial expression enhances Escherichia coli virulence for the urinary tract. Proc Natl Acad Sci U S A 93, 9827-9832.

Datsenko, K. A. \& Wanner, B. L. (2000). One-step inactivation of chromosomal genes in Escherichia coli K-12 using PCR products. Proc Natl Acad Sci U S A 97, 6640-6645.

Dziva, F., van Diemen, P. M., Stevens, M. P., Smith, A. J. \& Wallis, T. S. (2004). Identification of Escherichia coli O157 : H7 genes influencing colonization of the bovine gastrointestinal tract using signature-tagged mutagenesis. Microbiology 150, 3631-3645.

Eto, D. S., Sundsbak, J. L. \& Mulvey, M. A. (2006). Actin-gated intracellular growth and resurgence of uropathogenic Escherichia coli. Cell Microbiol 8, 704-717.

Forsman, K., Goransson, M. \& Uhlin, B. E. (1989). Autoregulation and multiple DNA interactions by a transcriptional regulatory protein in E. coli pili biogenesis. EMBO J 8, 1271-1277.

Foxman, B. (2002). Epidemiology of urinary tract infections: incidence, morbidity, and economic costs. Am J Med 113 (Suppl. 1A), 5S-13S.

Gander, R. M. \& Thomas, V. L. (1987). Distribution of type 1 and P pili on uropathogenic Escherichia coli O6. Infect Immun 55, 293-297.

Guzman, L. M., Belin, D., Carson, M. J. \& Beckwith, J. (1995). Tight regulation, modulation, and high-level expression by vectors containing the arabinose PBAD promoter. J Bacteriol 177, 4121-4130.

Holden, N. J. \& Gally, D. L. (2004). Switches, cross-talk and memory in Escherichia coli adherence. J Med Microbiol 53, 585-593.

Kallenius, G., Mollby, R., Svenson, S. B., Helin, I., Hultberg, H., Cedergren, B. \& Winberg, J. (1981). Occurrence of P-fimbriated Escherichia coli in urinary tract infections. Lancet 2, 1369-1372.
Khan, A. S., Kniep, B., Oelschlaeger, T. A., Van Die, I., Korhonen, T. \& Hacker, J. (2000). Receptor structure for F1C fimbriae of uropathogenic Escherichia coli. Infect Immun 68, 3541-3547.

Kjaergaard, K., Schembri, M. A., Hasman, H. \& Klemm, P. (2000a). Antigen 43 from Escherichia coli induces inter- and intraspecies cell aggregation and changes in colony morphology of Pseudomonas fluorescens. J Bacteriol 182, 4789-4796.

Kjaergaard, K., Schembri, M. A., Ramos, C., Molin, S. \& Klemm, P. (2000b). Antigen 43 facilitates formation of multispecies biofilms. Environ Microbiol 2, 695-702.

Klemm, P. (1986). Two regulatory fim genes, fimB and fimE, control the phase variation of type 1 fimbriae in Escherichia coli. EMBO J 5, 1389-1393.

Klemm, P. \& Christiansen, G. (1987). Three fim genes required for the regulation of length and mediation of adhesion of Escherichia coli type 1 fimbriae. Mol Gen Genet 208, 439-445.

Klemm, P. \& Schembri, M. A. (2000). Bacterial adhesins: function and structure. Int J Med Microbiol 290, 27-35.

Klemm, P., Christiansen, G., Kreft, B., Marre, R. \& Bergmans, H. (1994). Reciprocal exchange of minor components of type 1 and F1C fimbriae results in hybrid organelles with changed receptor specificities. J Bacteriol 176, 2227-2234.

Klemm, P., Jorgensen, B. J., Kreft, B. \& Christiansen, G. (1995). The export systems of type 1 and $\mathrm{F} 1 \mathrm{C}$ fimbriae are interchangeable but work in parental pairs. J Bacteriol 177, 621-627.

Klemm, P., Schembri, M., Stentebjerg-Olesen, B., Hasman, H. \& Hasty, D. L. (1998). Fimbriae: detection, purification and characterization. Methods Microbiol 27, 239-248.

Korhonen, T. K., Vaisanen-Rhen, V., Rhen, M., Pere, A., Parkkinen, J. \& Finne, J. (1984). Escherichia coli fimbriae recognizing sialyl galactosides. J Bacteriol 159, 762-766.

Lam, J. S. \& Mutharia, L. M. (1994). Antigen-antibody reactions. In Methods for General and Molecular Bacteriology, pp. 104-132. Edited by P. Gerhardt. Washington, DC: American Society for Microbiology.

Leffler, H. \& Svanborg-Eden, C. (1981). Glycolipid receptors for uropathogenic Escherichia coli on human erythrocytes and uroepithelial cells. Infect Immun 34, 920-929.

Low, A. S., Dziva, F., Torres, A. G., Martinez, J. L., Rosser, T., Naylor, S., Spears, K., Holden, N., Mahajan, A. \& other authors (2006a). Cloning, expression, and characterization of fimbrial operon F9 from enterohemorrhagic Escherichia coli O157: H7. Infect Immun 74, 2233-2244.

Low, A. S., Holden, N., Rosser, T., Roe, A. J., Constantinidou, C., Hobman, J. L., Smith, D. G., Low, J. C. \& Gally, D. L. (2006b). Analysis of fimbrial gene clusters and their expression in enterohaemorrhagic Escherichia coli O157 : H7. Environ Microbiol 8, 1033-1047.

Mobley, H. L., Green, D. M., Trifillis, A. L., Johnson, D. E., Chippendale, G. R., Lockatell, C. V., Jones, B. D. \& Warren, J. W. (1990). Pyelonephritogenic Escherichia coli and killing of cultured human renal proximal tubular epithelial cells: role of hemolysin in some strains. Infect Immun 58, 1281-1289.

Nowicki, B., Rhen, M., Vaisanen-Rhen, V., Pere, A. \& Korhonen, T. K. (1984). Immunofluorescence study of fimbrial phase variation in Escherichia coli KS71. J Bacteriol 160, 691-695.

Oelschlaeger, T. A., Dobrindt, U. \& Hacker, J. (2002a). Virulence factors of uropathogens. Curr Opin Urol 12, 33-38.

Oelschlaeger, T. A., Dobrindt, U. \& Hacker, J. (2002b). Pathogenicity islands of uropathogenic E. coli and the evolution of virulence. Int $J$ Antimicrob Agents 19, 517-521.

Old, D. C. \& Duguid, J. P. (1970). Selective outgrowth of fimbriate bacteria in static liquid medium. J Bacteriol 103, 447-456. 
Pere, A., Nowicki, B., Saxen, H., Siitonen, A. \& Korhonen, T. K. (1987). Expression of P, type 1, and type 1C fimbriae of Escherichia coli in the urine of patients with acute urinary tract infection. J Infect Dis 156, 567-574.

Pratt, L. A. \& Kolter, R. (1998). Genetic analysis of Escherichia coli biofilm formation: roles of flagella, motility, chemotaxis and type I pili. Mol Microbiol 30, 285-293.

Roos, V., Nielsen, E. M. \& Klemm, P. (2006a). Asymptomatic bacteriuria Escherichia coli strains: adhesins, growth and competition. FEMS Microbiol Lett 262, 22-30.

Roos, V., Ulett, G. C., Schembri, M. A. \& Klemm, P. (2006b). The asymptomatic bacteriuria Escherichia coli strain 83972 outcompetes uropathogenic E. coli strains in human urine. Infect Immun 74, 615624.

Sambrook, J., Fritsch, E. F. \& Maniatis, T. (1989). Molecular Cloning: a Laboratory Manual, 2nd edn. Cold Spring Harbor, NY: Cold Spring Harbor Laboratory.

Sauer, F. G., Remaut, H., Hultgren, S. J. \& Waksman, G. (2004). Fiber assembly by the chaperone-usher pathway. Biochim Biophys Acta 1694, 259-267.

Schembri, M. A. \& Klemm, P. (2001). Biofilm formation in a hydrodynamic environment by novel FimH variants and ramifications for virulence. Infect Immun 69, 1322-1328.

Schembri, M. A., Sokurenko, E. V. \& Klemm, P. (2000). Functional flexibility of the FimH adhesin: insights from a random mutant library. Infect Immun 68, 2638-2646.

Schembri, M. A., Kjaergaard, K. \& Klemm, P. (2003). Global gene expression in Escherichia coli biofilms. Mol Microbiol 48, 253-267.

Snyder, J. A., Haugen, B. J., Buckles, E. L., Lockatell, C. V., Johnson, D. E., Donnenberg, M. S., Welch, R. A. \& Mobley, H. L. (2004). Transcriptome of uropathogenic Escherichia coli during urinary tract infection. Infect Immun 72, 6373-6381.

Snyder, J. A., Haugen, B. J., Lockatell, C. V., Maroncle, N., Hagan, E. C., Johnson, D. E., Welch, R. A. \& Mobley, H. L. (2005). Coordinate expression of fimbriae in uropathogenic Escherichia coli. Infect Immun 73, 7588-7596.

Sokurenko, E. V., Courtney, H. S., Ohman, D. E., Klemm, P. \& Hasty, D. L. (1994). FimH family of type 1 fimbrial adhesins: functional heterogeneity due to minor sequence variations among fim $H$ genes. $J$ Bacteriol 176, 748-755.

Sokurenko, E. V., Schembri, M. A., Trintchina, E., Kjaergaard, K., Hasty, D. L. \& Klemm, P. (2001). Valency conversion in the type 1 fimbrial adhesin of Escherichia coli. Mol Microbiol 41, 675-686.

Stamm, W. E. (1991). Catheter-associated urinary tract infections: epidemiology, pathogenesis, and prevention. Am J Med 91, 65S-71S.
Stentebjerg-Olesen, B., Chakraborty, T. \& Klemm, P. (2000). FimEcatalyzed off-to-on inversion of the type 1 fimbrial phase switch and insertion sequence recruitment in an Escherichia coli K-12 fimB strain. FEMS Microbiol Lett 182, 319-325.

Svanborg, C., Bergsten, G., Fischer, H., Godaly, G., Gustafsson, M., Karpman, D., Lundstedt, A. C., Ragnarsdottir, B., Svensson, M. \& Wullt, B. (2006). Uropathogenic Escherichia coli as a model of hostparasite interaction. Curr Opin Microbiol 9, 33-39.

Ulett, G. C., Bohnsack, J. F., Armstrong, J. \& Adderson, E. E. (2003). Beta-hemolysin-independent induction of apoptosis of macrophages infected with serotype III group B streptococcus. J Infect Dis 188, 1049-1053.

Ulett, G. C., Webb, R. I. \& Schembri, M. A. (2006). Antigen-43mediated autoaggregation impairs motility in Escherichia coli. Microbiology 152, 2101-2110.

van Die, I., Kramer, C., Hacker, J., Bergmans, H., Jongen, W. \& Hoekstra, W. (1991). Nucleotide sequence of the genes coding for minor fimbrial subunits of the F1C fimbriae of Escherichia coli. Res Microbiol 142, 653-658.

van Diemen, P. M., Dziva, F., Stevens, M. P. \& Wallis, T. S. (2005). Identification of enterohemorrhagic Escherichia coli $\mathrm{O} 26$ : $\mathrm{H}-$ genes required for intestinal colonization in calves. Infect Immun 73, 17351743.

Vidal, O., Longin, R., Prigent-Combaret, C., Dorel, C., Hooreman, M. \& Lejeune, P. (1998). Isolation of an Escherichia coli K-12 mutant strain able to form biofilms on inert surfaces: involvement of a new $\operatorname{ompR}$ allele that increases curli expression. J Bacteriol 180, 2442-2449.

Webster, N. S., Smith, L. D., Heyward, A. J., Watts, J. E., Webb, R. I., Blackall, L. L. \& Negri, A. P. (2004). Metamorphosis of a scleractinian coral in response to microbial biofilms. Appl Environ Microbiol 70, 1213-1221.

Welch, R. A., Burland, V., Plunkett, G., III, Redford, P., Roesch, P., Rasko, D., Buckles, E. L., Liou, S. R., Boutin, A. \& other authors (2002). Extensive mosaic structure revealed by the complete genome sequence of uropathogenic Escherichia coli. Proc Natl Acad Sci U S A 99, 17020-17024.

Wu, X. R., Sun, T. T. \& Medina, J. J. (1996). In vitro binding of type 1fimbriated Escherichia coli to uroplakins Ia and Ib: relation to urinary tract infections. Proc Natl Acad Sci U S A 93, 9630-9635.

Xia, Y., Gally, D., Forsman-Semb, K. \& Uhlin, B. E. (2000). Regulatory cross-talk between adhesin operons in Escherichia coli: inhibition of type 1 fimbriae expression by the PapB protein. EMBO J 19, 14501457.

Edited by: M. P. Stevens 